\title{
Retroflection from a double-slanted coastline: a model for the Agulhas leakage variability
}

\author{
V. Zharkov ${ }^{1}$, D. Nof ${ }^{1,2}$, and W. Weijer ${ }^{3}$ \\ ${ }^{1}$ Geophysical Fluid Dynamics Institute, Florida State University, Tallahassee, FL, 32306, USA \\ ${ }^{2}$ Department of Oceanography, Florida State University, Tallahassee, FL, 32306, USA \\ ${ }^{3}$ New Mexico Consortium, Los Alamos National Laboratory, Los Alamos, NM 87545, USA
}

Received: 26 March 2010 - Published in Ocean Sci. Discuss.: 5 July 2010

Revised: 9 November 2010 - Accepted: 10 November 2010 - Published: 13 December 2010

\begin{abstract}
The Agulhas leakage to the South Atlantic exhibits a strong anti-correlation with the mass flux of the Agulhas Current. When the Agulhas retroflection is in its normal position near Cape Agulhas, leakage is relatively high and the nearby South African coastal slant (angle of derivation from zonal) is very small and relatively invariant alongshore. During periods of strong incoming flux (low leakage), the retroflection shifts upstream to Port Elizabeth or East London, where the coastline shape has a "kink", i.e., the slant changes abruptly from small on the west side, to large (about $55^{\circ}$ ) on the east side. Here, we show that the variability of rings shedding and anti-correlation between Agulhas mass flux and leakage to the South Atlantic may be attributed to this kink.

To do so, we develop a nonlinear analytical model for retroflection near a coastline that consists of two sections, a zonal western section and a strongly slanted eastern section. The principal difference between this and the model of a straight slanted coast (discussed in our earlier papers) is that, here, free purely westward propagation of eddies along the zonal coastline section is allowed. This introduces an interesting situation in which strong slant of the coast east of the kink prohibits the formation and shedding of rings, while the almost zonal coastal orientation west of the kink encourages shedding. Therefore, the kink "locks" the position of the retroflection, forcing it to occur just downstream of the kink. Rings are necessarily shed from the retroflection area in our kinked model, regardless of the degree of eastern coast slant. In contrast, a no-kink model with a coastline of intermediate slant indicates that shedding is almost completely arrested by that slant.
\end{abstract}

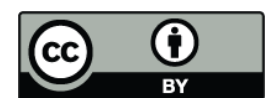

Correspondence to: D. Nof (nof@ocean.fsu.edu)
We suggest that the observed difference in ring-shedding intensity during times of normal retroflection position and times when the retroflection is shifted eastward is due to the change in the retroflection location with respect to the kink. When the incoming flux detaches from the coast north of the kink, ring transport is small; when the flux detaches south of the kink, transport is large. Simple process-oriented numerical simulations are in fair agreement with our analytical results.

\section{Introduction}

The normal retroflection position of the Agulhas Current (AC) is to the southwest of Cape Agulhas (Lutjeharms and Van Ballegooyen, 1988a). Occasionally, however, the retroflection shifts upstream and occurs near Port Elizabeth or East London (Fig. 1, upper panel). This unusual eastward shift typically occurs during periods of strong incoming flux (SIF). The coastline geometries near the two different retroflection areas are distinctly different. During SIF, retroflection occurs near a coastline that is strongly concave (i.e., in plan view, the on-land angle between the two straight coasts is considerably smaller than $180^{\circ}$ ), whereas during times of normal position of retroflection (NPR), the nearby coastline is weakly concave.

This article supplements our recent theoretical investigations suggesting that Agulhas ring-shedding variability is primarily due to the inertial and momentum imbalances in combination with the coastal slant (deviation from zonal orientation) near the retroflection (Zharkov and Nof, 2008a, b: hereafter referred to as $\mathrm{ZNa}, \mathrm{ZNb}$, and, jointly, $\mathrm{ZNab}$ ). Here we push our recent work closer to reality by introducing a "kink" in the previously straight coastline configuration.

Published by Copernicus Publications on behalf of the European Geosciences Union. 

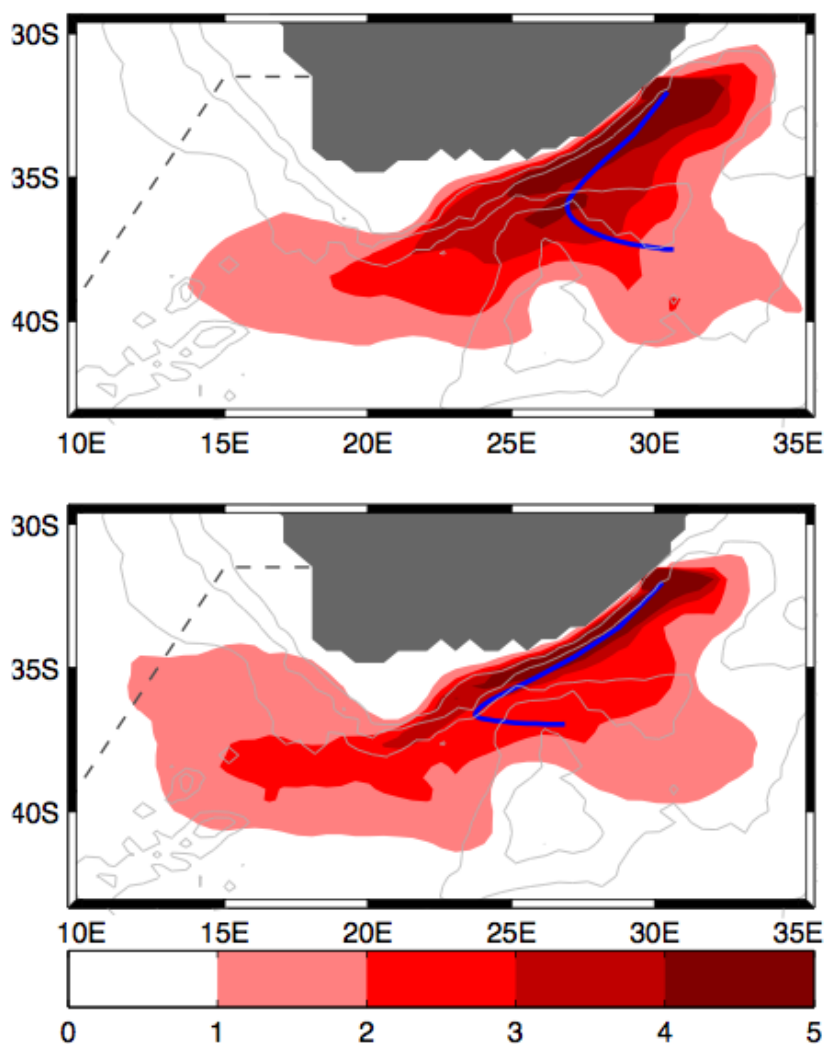

Fig. 1. The transport density (shaded patches, in Sv) based on floats distribution. Upper panel: the first six months after release of all floats in 1986-1987, when the AC transport was 65.4 Sv. Lower panel: the same but for 1988-1989, when the AC transport was $61.0 \mathrm{~Sv}$. The thick blue lines show the transport mean trajectories. Bathymetry is shown by the gray lines $(1500 \mathrm{~m}$ contour interval). The dashed line is the location of the Good Hope line over which the Agulhas leakage is calculated. During the time of lower transport (lower panel), the current detaches from the continental slope farther downstream. The retroflection is consequently moved westward and the magnitude of the Agulhas leakage is increased. Adapted from Van Sebille (2009).

This refinement allows us to mimic more closely the actual coastline orientation. In a (land) concave model the land protrudes toward the ocean so that the ocean occupies more than half the $360^{\circ}$ plane. In the convex model, the ocean bulges into the land so that it occupies less than half the $360^{\circ}$ plane. The former case is applicable to the southern tip of Africa, whereas the latter is more appropriate to the southwest Atlantic. Our focus here will be on the South African case.

\subsection{Observational background}

Although the positions of retroflected currents are in general determined by the position of the zero wind stress curl, the exact path and position of the $\mathrm{AC}$ retroflection adjacent to the coastline is sensitive to various parameters such as the $\mathrm{AC}$ volume transport and the coastline orientation (see e.g., Lut- jeharms and Van Ballegooyen, 1984). During NPR, when the $\mathrm{AC}$ volume transport is low, the Agulhas retroflection protrudes westward and is located near a coastline of low slant and little curvature. During these times, there is an increase of warm water influx (via rings) into the South Atlantic. During SIF, on the other hand, the retroflection shifts eastward to a location where the coastline has a concave "kink" (i.e., where the on-land angle between the two approximately straight coastlines is considerably smaller than $180^{\circ}$ ). This is probably consistent with the observation that rings in the Agulhas region are typically shed about 5-6 times per year, but the period of their formation increases sometimes to almost half-a-year (e.g., Byrne et al., 1995; Gordon et al., 1987; Lutjeharms, 2006; Schouten et al., 2000; Van Aken et al., 2003).

Interestingly, there is no consensus on the significance of seasonal variability of the retroflection and other Agulhas features and processes. Shannon (1985), and Esper et al. (2004) point to a seasonal variability of the retroflection position, which is in agreement with the numerical calculations of Reason et al. (2003) suggesting that the incoming flux is maximal in winter and minimal in summer. Ffield et al. (1997) also point to seasonal variation in the Agulhas volume transport, and some seasonality in the Agulhas sea surface height was also shown by Matano et al. (1998). Goni et al. (1997) suggest that seasonality can very moderately affect ring shedding. Their observations during 1992-1995 suggest that six out of the 17 consecutive Agulhas rings were first observed in austral summers while only four rings were first observed in winters. In addition, the volumes of all four winter-rings were less than the value averages over all rings. However, such volume variations are not commonly believed to be responsible for significant seasonal modifications of the rings' shedding regime (e.g., Van Sebille, 2009).

In contrast to the above ideas of seasonality, Lutjeharms and Van Ballegooyen (1988b), and Lutjeharms (2006) speak about anomalous and more occasional eastward shifts of the Agulhas retroflection area. Associated with these shifts is a decrease in ring shedding.

The anomalous eastward migration of Agulhas retroflection occurs usually 2-3 times per year and lasts 3-6 weeks. There have also been observations of very irregular, interannual variations of the retroflection position. For instance, the so-called "early (upstream) retroflection" events occurred in 1986 (Shannon et al., 1990) and in 2000-2001 (Quartly and Srokosz, 2002; De Ruijter et al., 2004), when the AC retroflected to the east of the Agulhas Plateau. A decrease in Agulhas leakage in 1986 (during the first known early retroflection) is clearly seen in Fig. 6 of Van Sebille et al. (2009b). During the second early retroflection event (2000-2001), no eddies were shed for about five months.

De Ruijter et al. (2004) suggest that the strong reduction (or even shutoff) of leakage via rings is due to LaNiña. By contrast, enhanced leakage occurs during El-Niño. This is in accordance with (our) Fig. 1 adopted from Van Sebille (2009) and suggesting that La-Niña event occurred 
in 1986-1987 (upper panel) whereas El-Niño occurred in 1988-1989 (lower panel). We can expect the time periods between consecutive La-Niña events to be comparable to the classic ENSO periods but with no regularity. (Note that in Biastoch et al., 2008, they are two years apart.) In addition, duration of La-Niña events in the Indian Ocean and the AC are much shorter than for the usual La-Niña conditions in the Pacific (see e.g., Van Sebille et al., 2009a, VSa, hereafter).

\subsection{Theoretical background}

An anti-correlation between the AC transport and the westward protrusion of the retroflection (and, therefore, increase in Agulhas leakage) has been pointed out by De Ruijter and Boudra (1985), Boudra and Chassignet (1988), Esper et al. (2004), and VSa. It has also been shown that the position of Agulhas retroflection has a strong impact on the interannual variations of the inflow to the South Atlantic, which, in turn, significantly affects the decadal variability in the Atlantic meridional overturning circulation (Weijer et al., 1999, 2002; Biastoch et al., 2008). While all of these studies are informative, none specifically addresses the dynamic balance involved in the anti-correlation modeling.

The idea that coastal geometry is important to retroflecting currents is also not new. It was recognized by $\mathrm{Ou}$ and De Ruijter (1986), Boudra and Chassignet (1988), De Ruijter et al. (1999), Chassignet and Boudra (1988), and Pichevin et al. (1999), though none of these earlier studies focused specifically on the issue that we are addressing here, where a small slant allows for stronger eddy production.

Of these earlier studies, Ou and De Ruijter (1986) is the closest to our new kink model. Here the authors assumed that the flow has a scale larger than the Rossby radius and that the flow scale is also larger than the continental radius of curvature. In their model, the AC attempts to follow the coastline but cannot continue to do so when the coastline curves strongly to the right (looking downstream) because the curving is too sharp for the current to mimic. Consequently, the current separates from the continent and a space opens up between the two. In its unsuccessful attempt to continue hugging the continent, the current cyclonically loops upon itself in this open space. Supposedly, this looping produces the retroflecting eddies. The main weakness of this theory is that it requires a relatively large coastline curvature for ring production, and so this model cannot be used to trace the dynamics of shedding in areas of only weak curvature. Also, according to this theory, the thermocline outcropping is a necessary condition for detachment of the AC from the coast.

For the case of a nearly zonal coastline and within a 1.5layer model, Nof and Pichevin (1996) showed that baroclinic rings are generated to compensate for the eastward retroflecting current momentum flux (flow-force). ZNa elaborated on this condition and pointed out a "vorticity paradox": only rings with strong relative vorticity satisfy the equations of momentum and mass conservation. Mathematically, this means that the ratio, $\Phi$, of the mass flux going into eddies to the incoming mass flux is $4 \alpha /(1+2 \alpha)$, where $\alpha$ is the eddy intensity coefficient (the eddy's orbital velocity is $\alpha f R / 2$ where $R$ is the eddy radius and $f$ is the Coriolis parameter; in the case of zero PV, $\alpha$ is 1). Therefore, the necessary condition $\Phi \leq 1$ is satisfied only for $\alpha \leq 0.5$. This is because, in the strong inertial limit $(\alpha>1 / 2)$, the momentum flux of the retroflecting current is just too high for rings to compensate for it, no matter how many rings are produced and no matter how large they are. One way to avoid this paradox is to focus on currents retroflecting near coastlines with slants larger than a threshold value $\left(\sim 15^{\circ}\right)$.

$\mathrm{ZNb}$ considered the case of a single straight coastline and showed that the value of $\Phi$ decreases monotonically to zero as the slant grows from zero to $90^{\circ}$. A critical coastline slant was defined, below which there is rings shedding and above which there is almost no shedding. Indeed, in the case of a meridionally directed incident current, no eddy detachment has been found in numerical models (Arruda et al., 2004).

\subsection{Present approach}

In this paper, we take a step closer to reality by considering a retroflection along a coast with a kink, i.e., a concave or convex coast consisting of two straight coastlines with different angles of slant. It can be inferred from Pichevin et al. (2009), as well as from others, that the effect of an abrupt change of slant is significant when the distance between the point of coastal inflection and the point of the AC coastal detachment is within the ring diameter. It will become clear later that this appears to be the case fairly often because the kink locks the position of the retroflection.

We shall consider three separate cases: Concave I, Concave II and Concave III. In Concave I, the western segment of the coastline is purely zonal. This is a special case has application to both NPR and SIF conditions; the eastern angle of slant will be smaller for the NPR case. Concaves II and III will be considered as simplifications of the South African coast geometry (Fig. 2), in that the western segment will no longer be constrained to a purely zonal orientation. In Concave II, which is meant to approximate the coastline near the retroflection during NPR, the angle between the two (nonzonal) coastlines is almost $180^{\circ}$ so the degree of concavity is weak. In Concave III, which represents the coastline near the retroflection during SIF, the angle is much smaller so the system is sharply concave. We will develop a nonlinear retroflection model (Fig. 3) using the slowly varying approach suggested by Nof (2005).

In considering the model geometry, we will neglect the varying offshore bathymetry even though the southern $\mathrm{AC}$ is steered by the shelf break rather than the coastline (Lutjeharms, 2006). This simplification is justified because when the retroflection occurs not far from the concavity of the coastline, the shelf break and coastline are parallel. Also, 


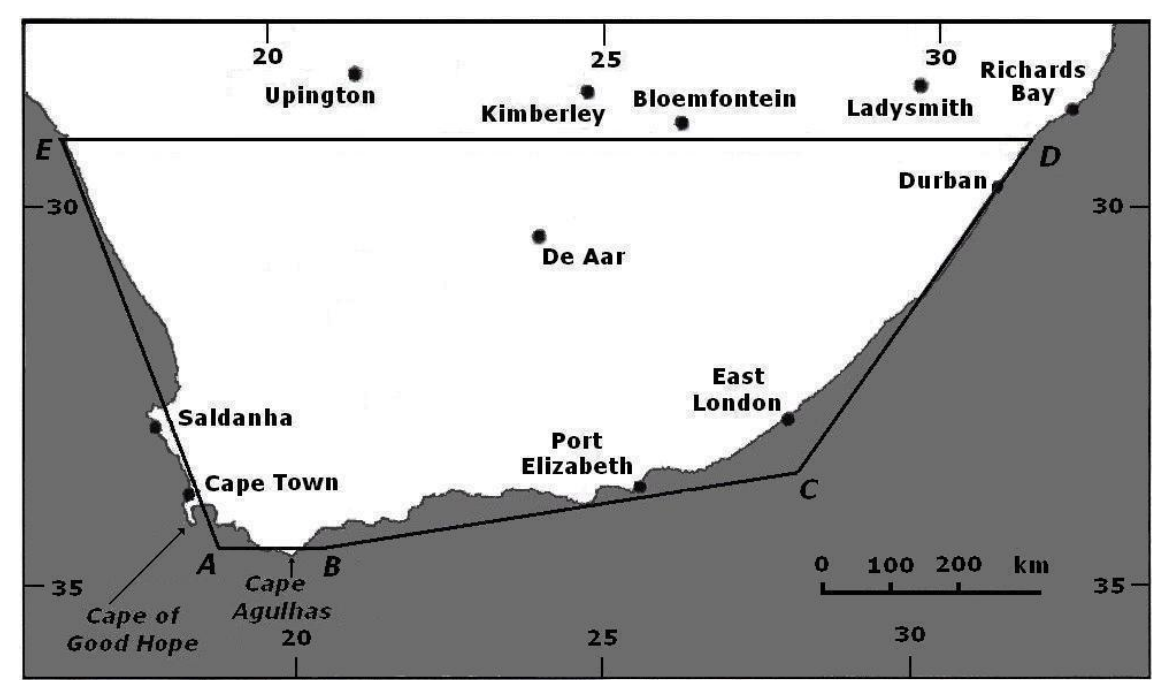

Fig. 2. Map of South Africa with a superimposed pentagon showing the model geometries. ABC corresponds to Concave II (coastline representation for NPR), and BCD corresponds to Concave III (SIF). Concave I is a zonal south-facing coastline contiguous with a slanted eastern shore (that could be NPR or SIF represented by different angles of slant or a mean slant).

rings shed from the eastward-shifted retroflection propagate westward and avoid the southern part of the Agulhas Bank because its scale is smaller than the scale of one separated eddy.

There are two important differences between the kink and the no-kink models. First, in the kink model, rings can escape from the generation area faster than in the no-kink model because in the no-kink model the rings are forced into the slanted wall. By contrast, in the kinked model, the rings are almost completely free to propagate westward. This implies that more rings will be generated in the kinked model because they can quickly escape a recapture by the new rings generated behind them. Second, the momentum flux in the direction corresponding to the rings' migration route (almost zonal) is smaller in the kinked model than in the nokink model because this flux corresponds to merely a component $(\cos \gamma)$ of the upstream longshore momentum. This implies fewer and smaller eddies in the kinked-model case. These two processes above compete, with the first encouraging and the second inhibiting ring production in the kinked model. Which one dominates depends on the particular circumstances. In the cases that we considered, the first process dominates, i.e., there are considerably more rings produced in the kinked model case.

This paper is not self-contained. Readers interested in further details may consult ZNab. In Sect. 2, we introduce the governing equations that control the development of the base eddy on a kinked coastline. In Sect. 3, we present model solutions for cases of varied parameters $\alpha$ and $\gamma$. Section 4 is devoted to an examination of ring size, drift speed, and shedding period. In Sect. 5, we give the results of numerical simulations and compare them with the analytics. Section 6 is devoted to an application of our results to the variability in Agulhas ring shedding and leakage into the South Atlantic via rings. Finally, we summarize and discuss our results in Sect. 7.

\section{Statement of problem}

As in ZNab, we consider a boundary current (with density $\rho$ ) embedded in an infinitely deep, stagnant lower layer (whose density is $\rho+\Delta \rho$ ), except that here the vertical boundary on the west is not a single straight line. The first coastline to be considered (Concave I) consists of two rectilinear sections (Fig. 3): one is zonal, and the second one is slanted at an angle $\gamma$ that varies between $0^{\circ}$ and $90^{\circ}$. The current flows southwestward along the slanted section and then retroflects south of the kink.

As mentioned, the main differences between the kinked case considered here and the no-kink model considered in $\mathrm{ZNab}$ are: (i) here, the rings escape from the generation area faster than in the no-kink case (because they no longer run into the wall), implying a larger production of rings, and (ii) here, the zonal component of the upstream momentumflux zonal component is smaller, leading to a smaller production of eddies. Which of the two competing processes dominates depends on the problem's particular conditions. In all the cases we looked at, the first process dominates. Note that the appropriate momentum-flux to consider here is the zonal one (not the slanted), because the rings are generated just downstream of the kink and start migrating westward right away. The numerics will later verify this assessment. Using the same notation used by ZNab (see Table A1 in Appendix), one ultimately finds the following equation for the ring radius 


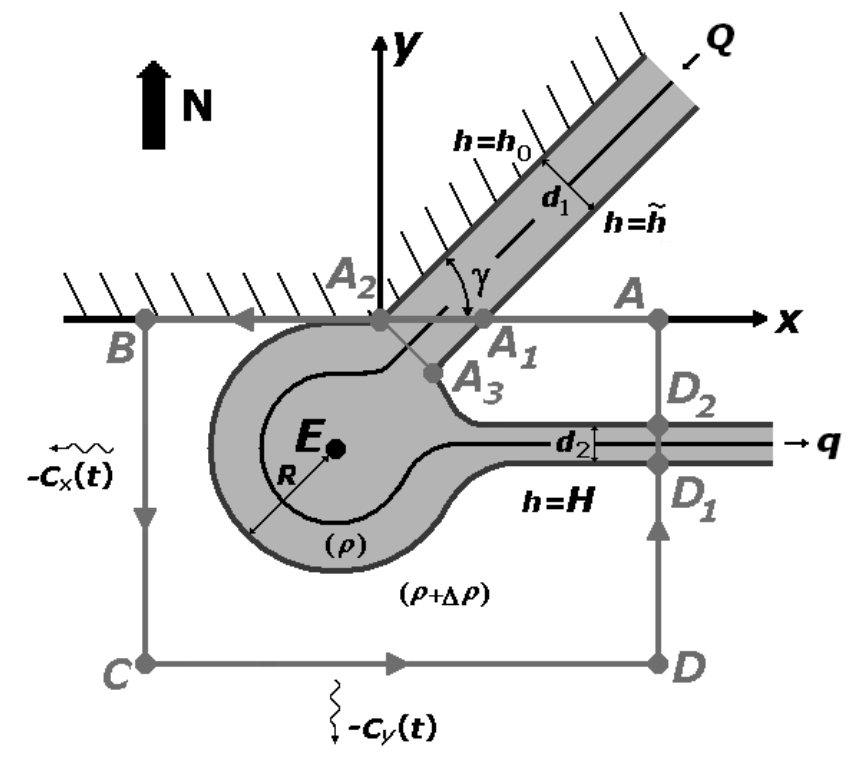

Fig. 3. Schematic diagram of the Concave I case: a zonal western shoreline segment with a slanted coastline $\left(\gamma=0\right.$ to $\left.90^{\circ}\right)$ to the east. The hatch marks indicate land. $E$ is the center of the base eddy. The incoming flux $Q$ flows along the wall, and the outgoing (retroflected) flux $q$ is directed to the east. The widths of the currents are $d_{1}$ and $d_{2}$, respectively. The "wiggly" arrows indicate the migration of the base eddy; this migration results from both the eddy growth, which forces the eddy away from the zonal wall, and from $\beta$, which forces the eddy along this wall. The migration velocity component $-C_{y}(t)$ is primarily due to eddy growth, whereas $-C_{x}(t)$ is primarily due to $\beta$. The thick grey line (with arrows) indicates the integration path, $\mathrm{ABCDA} ; \tilde{\mathrm{h}}$ is the upper layer thickness of the stagnant region wedged between the upstream and retroflecting currents, and $H$ is the off-shore thickness. The ring forms downstream of $A_{2}$ and immediately starts migrating westward. Consequently, the integrated momentum flux along the slanted wall involves an unknown force acting on the wall (and therefore cannot be used) but the zonal integrated momentum does not.

$R$ as a function of time $t$,

$$
\begin{aligned}
& \frac{\left(\alpha f_{0}\right)^{3}}{240}\left[2(1+\cos \gamma) R^{5}-5\left(\delta_{1}^{2}-\delta_{2}^{2}\right) R^{3}-5\left(\delta_{1}^{3} \cos \gamma+\delta_{2}^{3}\right)\right. \\
& \left.R^{2}+\left(3 \delta_{1}^{5} \cos \gamma+5 \delta_{1}^{2} \delta_{2}^{3}-2 \delta_{2}^{5}\right)\right]+\frac{\alpha^{2} f_{0} g^{\prime} h_{0}}{12} \\
& {\left[(1+\cos \gamma) R^{3}-\left(\delta_{1}^{3} \cos \gamma+\delta_{2}^{3}\right)\right]-\pi R^{2}} \\
& {\left[g^{\prime} H+\frac{\alpha(2-\alpha) f_{0}^{2} R^{2}}{16}\right] \frac{d R}{d t}=0 .}
\end{aligned}
$$

This equation differs from its counterpart in $\mathrm{ZNa}$ in that Eq. (1) the ZNa terms with $\alpha \beta R^{2}$ are absent here, and Eq. (2) in $\mathrm{ZNa} \cos \gamma$ serves as a multiplier for other terms than here in Eq. (1). The remaining equations defining the functions $R(t)$ and $\Phi(t)$ are the same as in $\mathrm{ZNa}$ and are not reproduced here.

\section{Solution}

We solved the system of equations, again by using the Runge-Kutta method of the fourth order. We used: $Q=$ $70 \mathrm{~Sv} ; g^{\prime}=2 \times 10^{-2} \mathrm{~ms}^{-2} ; f=8.8 \times 10^{-5} \mathrm{~s}^{-1}$ (corresponding to $35^{\circ}$ of latitude) and, we considered two cases of $h_{0}: 0 \mathrm{~m}$ and $300 \mathrm{~m}$. The parameter $\alpha$ was varied between 0.1 and 1.0, and $\gamma$ was varied between $0^{\circ}$ and $90^{\circ}$. The functions $R(t)$ and $\Phi(t)$ for the case of zero PV $(\alpha=1), h_{0}=300 \mathrm{~m}$, and $\beta=2.3 \times 10^{-11} \mathrm{~m}^{-1} \mathrm{~s}^{-1}$ are shown in Fig. 4 (left panels). For a comparison, analogous plots (without triangles and squares) for the $\mathrm{ZNa}, \mathrm{ZNb}$ model are also shown (right panels). The quantitative difference between the two models is obvious. Only the curves for $\gamma=0^{\circ}$ are identical because the case of a zonal wall is the same in both models. In the kinked case, the $R$ values grow infinitely with $t$, and the $\Phi(t)$ curves approach asymptotic values that decrease with growing $\gamma$. As expected, in the case of a zonal wall $\left(\gamma=0^{\circ}\right)$, the asymptotic value is close to 4/3. All the curves for $\gamma<60^{\circ}$ intersect the "dead line" $\Phi=1$, indicating that the "vorticity paradox" occurs at the sections of curves above this line. We can see that the paradox could be circumvented only for $\gamma \geq 60^{\circ}$ (instead of $\gamma \geq 15^{\circ}$ as in the $\mathrm{ZNa}$ model), because it is for this minimal value of $\gamma$ that $\Phi$ does not intersect the deadline. The asymptotic value for $\gamma=90^{\circ}$ is close to $2 / 3$, indicating that this case is similar to the ballooning-ofoutflows problem (Nof and Pichevin, 2001).

For smaller values of $\alpha$ (vorticity coefficient), the curves of $R(t)$ and $\Phi(t)$ (not shown) are similar to those shown in Fig. 4 , but the asymptotical values of $\Phi$ go down with decreasing $\alpha$. As expected from the analytical model, these values can indeed be approximated by $2 \alpha(1+\cos \gamma) /(1+2 \alpha)$. This result implies that the detached rings compensate for the momentum of both the entire retroflected current and the zonal projection of the incoming current. Therefore, the "vorticity paradox" is circumvented when the slant of the tilted coastline section is not less than $\cos ^{-1}(1 / 2 \alpha)$, which is $60^{\circ}$ for zero $\mathrm{PV}(\alpha=1)$.

\section{Detachment of rings}

\subsection{Lower and upper boundaries for final eddy size}

Following $\mathrm{ZNb}$, the generation period for each individual ring is,

$t_{f}=\left(2 R_{f}+d\right) /\left|C_{x f}\right|$,

where $d$ is the distance between two consecutive rings, $C_{x}$ is the ring propagation rate in the zonal direction, and the subscript $f$ denotes the final value (i.e., the value at the time of detachment). The lower boundary for the final eddy size $\left(R_{f l}\right)$ is obtained from the condition of "kissing eddies", i.e., $d=0$. 

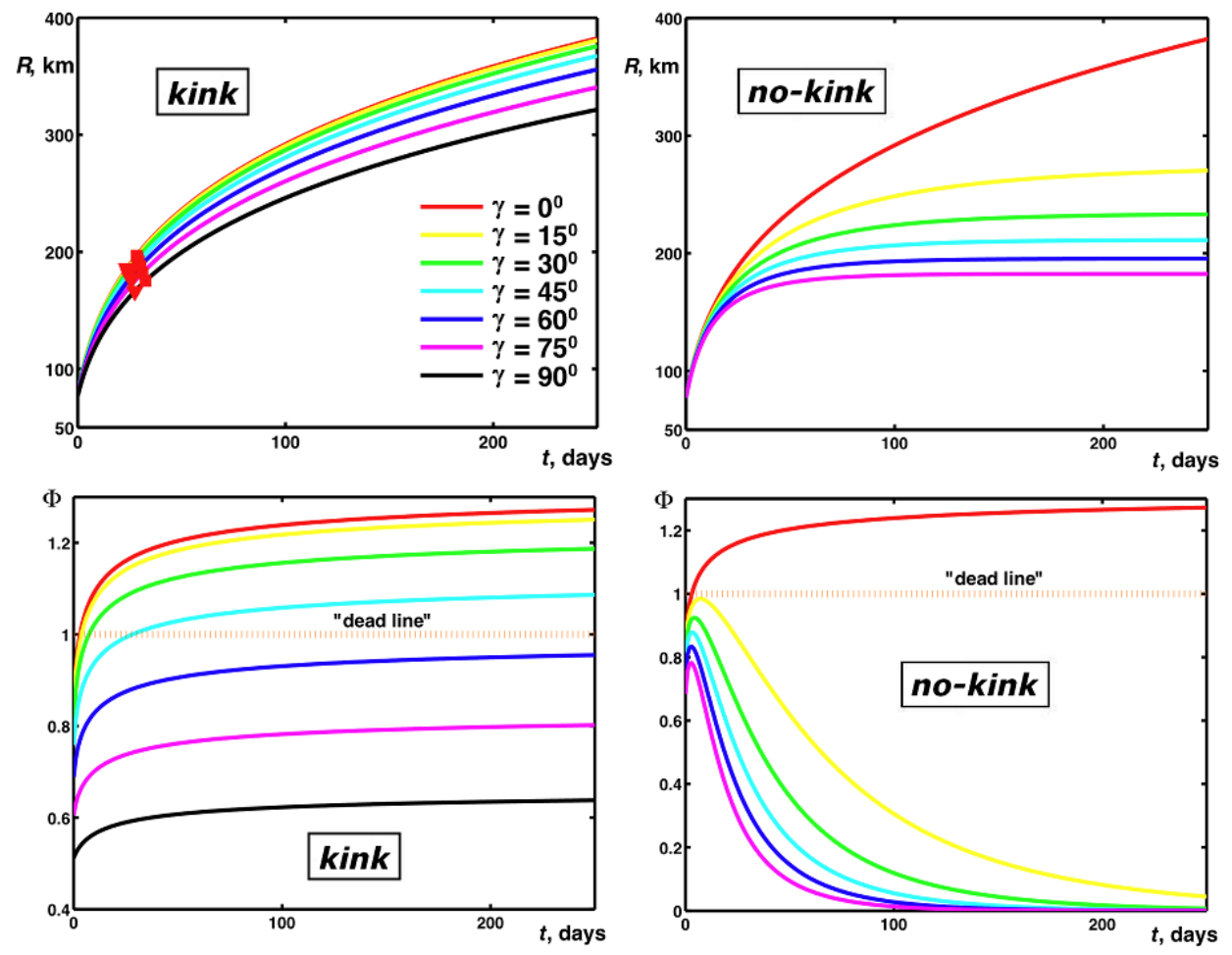

Fig. 4. Base eddy radius $R$ (upper panels) and mass flux ratio $\Phi$ (lower panels) as functions of time for different values of $\gamma$ : Concave I case (left) and analogous no-kink ZNa model (right). For the kink model, $\gamma$ indicates the angle of the eastern shoreline segment; for the no-kink model $\gamma$ indicates the angle of single-segment slant. The straight dotted "dead lines" (lower left panels) show the limit of $q=0$, $\Phi=1$. Red triangles and squares (upper left) denote the lower and upper boundaries of the detachment period for $\beta=2.3 \times 10^{-11} \mathrm{~m}^{-1} \mathrm{~s}^{-1}, \alpha=1$, $h_{0}=300 \mathrm{~m}$.

Next, we define the upper boundary $\left(R_{f u}\right)$ for the basic eddy's final size, and for the generation period $\left(t_{f u}\right)$. This expression implies that the ring can propagate at least its own diameter:

$$
\int_{0}^{t f u}\left|C_{x}\right| d t=2 R_{f u} .
$$

Physically, the upper boundary corresponds more directly to the detachment of isolated rings, whereas the lower boundary is a condition for the eddy chain formation. So, rings detach and propagate out of the retroflection area only when $R_{f l}$ is indeed less than $R_{f u}$.

\subsection{Analysis of lower and upper boundaries}

Here, we shall use $2.3 \times 10^{-11} \mathrm{~m}^{-1} \mathrm{~s}^{-1}$ and $6 \times 10^{-11} \mathrm{~m}^{-1}$ $\mathrm{s}^{-1}$ for $\beta$. The first is a commonly used value, whereas the second is magnified (more convenient for the model runs). The left upper panel of Fig. 5 shows $R_{f l}$ and $R_{f u}$ as functions of $\gamma$, and the right upper panel shows the analogous no-kink results. For both models, the functions decrease as $\gamma$ grows. In the kink (Concave I) case, the curves of $R_{f l}$ and $R_{f u}$ do not intersect, implying that there is no critical slant angle. The difference between the lower and upper size boundaries decreases slightly with diminishing $\alpha$. In the contrast, in the ZNb no-kink model, the lower and upper boundaries do intersect: the critical points of intersection are circled. (When the slant is supercritical, rings do not move out of the retroflection area fast enough and, consequently, they are recaptured by the flow behind.) In addition, in the $\mathrm{ZNb}$ model, the curves for $\alpha=1$ terminate at a value of $\gamma$ that is significantly less than $90^{\circ}$ because for large $\gamma$ and small $\alpha$, the base eddy is forced into the wall and is not allowed to grow. Such a process does not occur in the Concave I model considered here.

The ring detachment period $t_{f}$ (Fig. 5, second row) decreases with growing $\alpha$, as does the final eddy radius (first row). Here in the kink case, we again see no intersection or convergence of the curves depicting upper and lower boundaries (i.e., no critical angle). Eddy speed decreases with increasing $\alpha$ (Fig. 5, third row). Another difference between the kink model and the $\mathrm{ZNb}$ model is that the no-kink $t_{f l}$ and $t_{f u}$ tend to infinity and $C_{\xi l}$ and $C_{\xi u}$ go to zero when $\gamma \rightarrow 90^{\circ}$. This eddy shutdown does not occur in the kink model because when the retroflection occurs near the kink, detached eddies can now (Concave I) propagate westwards with no obstacles. 

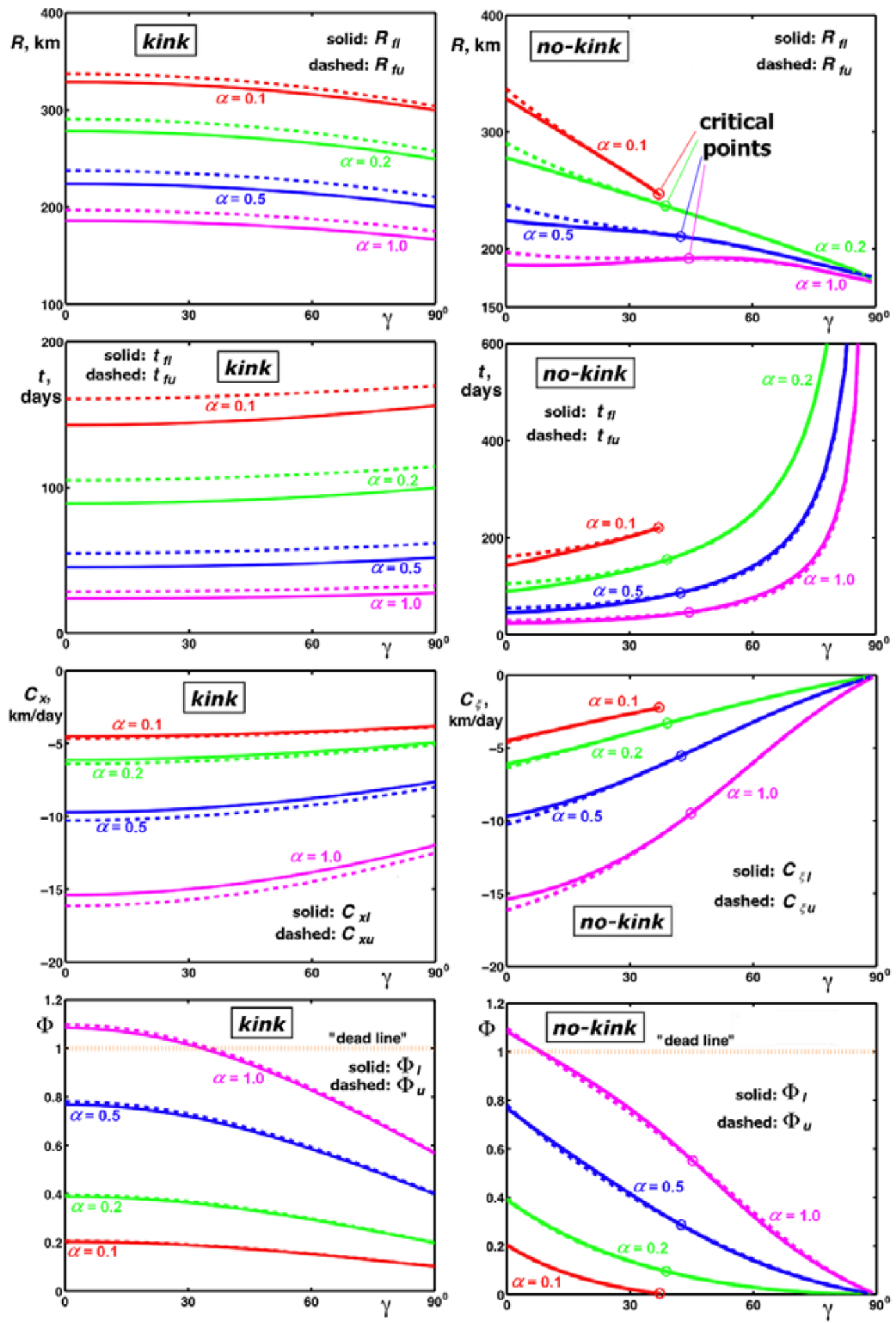

Fig. 5. Final base eddy radii $\left(R_{f l}\right.$ and $\left.R_{f u}\right)$, ring generation periods $\left(t_{f l}\right.$ and $\left.t_{f u}\right)$, ring zonal propagation rates $\left(C_{x l}\right.$ and $\left.C_{x u}\right)$, and mass flux ratios $\left(\Phi_{l}\right.$ and $\left.\Phi_{u}\right)$ as functions of $\gamma$ for Concave I (left panels) and analogous ZNb model parameters (right panels, with non-zonal ring propagation rates $C_{\xi} l$ and $C_{\xi} u$ ), for $h_{0}=300 \mathrm{~m}$ and $\beta=2.3 \times 10^{-11} \mathrm{~m}^{-1} \mathrm{~s}^{-1}$. The curves are paired, where solid and dashed lines show the lower and upper boundaries of the eddy radius, respectively. In the Concave I case, upper and lower boundaries do not intersect. In the $\mathrm{ZNb}$ model, upper and lower boundaries do intersect, implying the existence of critical slant angles. Such critical points are circled. 


\subsection{Mass flux going into rings}

We will now estimate $\Phi$, the ratio of mass flux going into the growth of the rings to the incoming flux. Because $\Phi$ depends on time, this ratio is obtained by averaging instantaneous values over the period of eddy generation. As expected, averaged values of $\Phi$ for both models decrease with increasing coastline slant $\gamma$ (Fig. 5, lower panels). In the kink model, the $\Phi_{u}$ and $\Phi_{l}$ curves for a given $\alpha$ do not intersect. In contrast, in the analogous $\mathrm{ZNb}$ case, the $\Phi$ curves intersect twice, first at points corresponding to $\gamma$ between $4^{\circ}$ and $35^{\circ}$, and then again at higher $\gamma$ when the angle is critical (and $\alpha>0.1$ ); Fig. 5, lower right panel). For both models, low-angle values of $\Phi$ fall above the "dead line" (i.e., appearance of the "vorticity paradox") for $\alpha>0.8$. Maximum time-averaged $\Phi$ values, which occur when $\alpha=1$, are considerably less than $4 / 3$, because the instantaneous values of $\Phi$ are much less than 1 at the beginning of eddy development. For $\gamma>34^{\circ}$, all the curves are below the dead line. Distinguished $\Phi$ characteristics for Concave I are as mentioned above: no critical angles, and $\Phi$ does not tend to zero with growing $\gamma$.

One can show that varying upper layer thickness has only a very weak influence on the detached rings (results not shown). Using the modified value of $\beta$ rather than the standard value does not lead to qualitative differences either. However, the propagation rate of rings increases, and the generation period decreases. Also, the lower and upper boundaries become close to each other for large $\gamma$, meaning that the shedding regime is nearly critical but not supercritical.

\section{Numerical simulations: Concave I}

As in our previous studies, we used a modified version of the Bleck and Boudra (1986) reduced gravity isopycnic model with a passive lower layer and the Orlanski (1976) secondorder radiation conditions for the open boundary. The basin size was taken to be $3200 \times 1600 \mathrm{~km}^{2}$. The continent (Figs. 6 and 7) was modeled by a fixed meridional western wall ( $600 \mathrm{~km}$ long), a southern wall that could be either $2200 \mathrm{~km}$ (in the case $\gamma=0^{\circ}$ ) or 1000-1200 km long, and, for $\gamma>0^{\circ}$, an eastern wall inclined by the angle $\gamma$ to the zonal direction ( $\gamma$ varied between $15^{\circ}$ and $90^{\circ}$ in steps of $15^{\circ}$ ). The walls were taken to be slippery.

The experiment began by turning on an outflow at $t=0$; the numerical source was an open channel containing streamlines parallel to the slanted wall in the incoming current and horizontal in the outgoing flow. The initial velocity profile across the channel was linear, and the thickness profile was parabolic. Because each run provides many data points, it is believed that we have enough data to work with. We chose the initial PV of outflows such that the starting values of $\alpha$ were $0.1,0.4$, and 1.0. As expected, at the beginning of each run when the orbital velocities were still high, $\alpha$ changed relatively quickly.
The numerical parameters were: (i) a time step of $120 \mathrm{~s}$; (ii) a grid step of $20 \mathrm{~km}$; (iii) a Laplacian viscosity coefficient of $\nu=700 \mathrm{~m}^{2} \mathrm{~s}^{-1}$ for $\gamma>15^{\circ}$ and for $\gamma=15^{\circ}, \alpha>0.1$; and $1000 \mathrm{~m}^{2} \mathrm{~s}^{-2}$ for $\gamma=15^{\circ}, \alpha=0.1$. Other parameters were $g^{\prime}=2 \times 10^{-2} \mathrm{~ms}^{-2}, f_{0}=8.8 \times 10^{-5} \mathrm{~s}^{-1}, Q=70 \mathrm{~Sv}, \beta=$ $2.3 \times 10^{-11} \mathrm{~m}^{-1} \mathrm{~s}^{-1}$ (realistic) or $6 \times 10^{-11} \mathrm{~m}^{-1} \mathrm{~s}^{-1}$ (magnified), and the initial value of $h_{0}=0$ or $300 \mathrm{~m}$. We ran all the experiments for a long time (about 210 days for most, but about 700 days for some), so that even the zero PV experiment ultimately had its PV strongly altered by the cumulative effects of friction. Therefore, we used time-averaged values of $\alpha$ in our quantitative comparisons. For most of the experiments, we chose the magnified value of $\beta$ which accelerates ring detachment and makes our runs more economical. For the realistic value of $\beta$, the model results do not qualitatively differ from those obtained with the magnified $\beta$, but the time required for the numerical runs does noticeably increase. In addition, for larger $\beta$, the effect of viscosity gets even stronger, which makes the view of some rings extremely fuzzy. Finally, increasing $\beta$ increases the ring propagation rate, compensating for the deceleration by viscosity.

Viscosity values used in these experiments may be considered high for studying an essentially inertial process like Agulhas ring shedding; however these values are essential to maintain numerical stability for the required duration of the experiments. Still, the relatively coarse resolution used in these experiments $(\sim 20 \mathrm{~km})$ assures clear dominance of inertial forces over viscous friction.

We examine first some general simulations not meant to represent NPR or SIF but to illustrate model dynamics at a fixed outflow latitude. For most Concave I cases, our numerical simulations (with $\gamma=15^{\circ}, 30^{\circ}$, and $45^{\circ}$ ) show the detachment of two or three rings from the retroflection area during the first 200 days (Fig. 6). As a secondary effect, the second eddy often collided with the first one. A similar effect was present in the numerical simulations of Pichevin et al. (1999), though the authors of that paper did not note it. Our simulations with $\gamma=60^{\circ}$ showed increased influence of some rings formed in the upstream flow (due to meandering, not retroflection). Such rings moved westward and reached the retroflection area but, upon approaching the developing base eddy, were weakened and did not affect it.

The simulations with $\gamma=75^{\circ}$ and $90^{\circ}$ confirm our conjecture that these angles are "almost critical" for modified $\beta$. Indeed, the runs with $\alpha=0.1$ were very similar to those for $\gamma=60^{\circ}$, i.e., there was a detachment of two eddies during the first 200 days. However, a more typical situation is displayed in Fig. $7\left(\gamma=75^{\circ}\right)$. During 300 days of simulation, only one eddy is detached, and a second one is about to be detached. Sometimes the meandering of the retroflected current becomes so strong that it leads to the formation of rings not only in the area of retroflection (i.e. base eddy) but also downstream in the outgoing jet and upstream, prior to the retroflection. Some of our runs show that such rings form and detach even earlier than the base eddy does, and they 

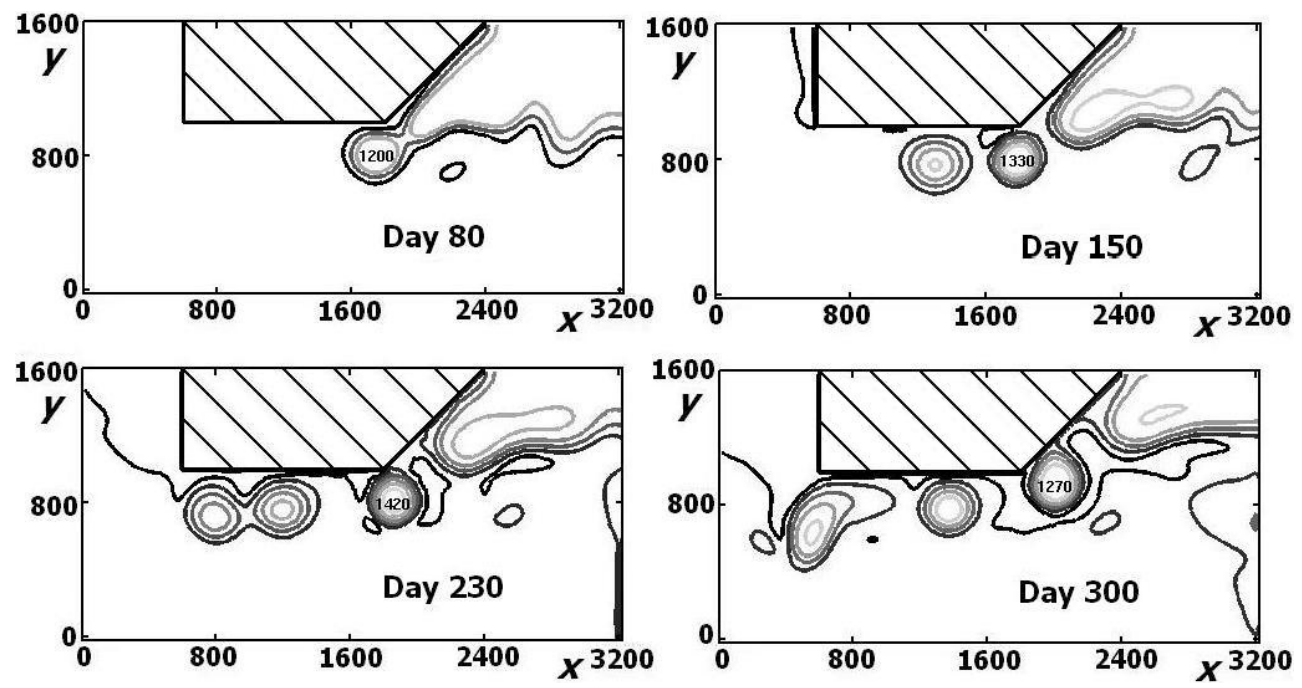

Fig. 6. Upper layer thicknesses for the case of a Concave I coastline with a modest kink (midsize $\gamma$ ) and a current with high upstream vorticity $\left(\gamma=45^{\circ}, \alpha=1, h_{0}=300 \mathrm{~m}, v=700 \mathrm{~m}^{2} \mathrm{~s}^{-1}\right.$, and $\left.\beta=6 \times 10^{-11} \mathrm{~m}^{-1} \mathrm{~s}^{-1}\right)$. The eastern wall is not critically slanted, so rings are formed upstream of the kink. Thicknesses are given in meters, and the $\mathrm{x}$ and y scales are in kilometers. This figure, as well as Fig. 7, is given here merely to illustrate the dynamics - both figures are not necessarily associated with either the SIF or NPR, whose numerical runs are displayed in Figs. 9 and 10.
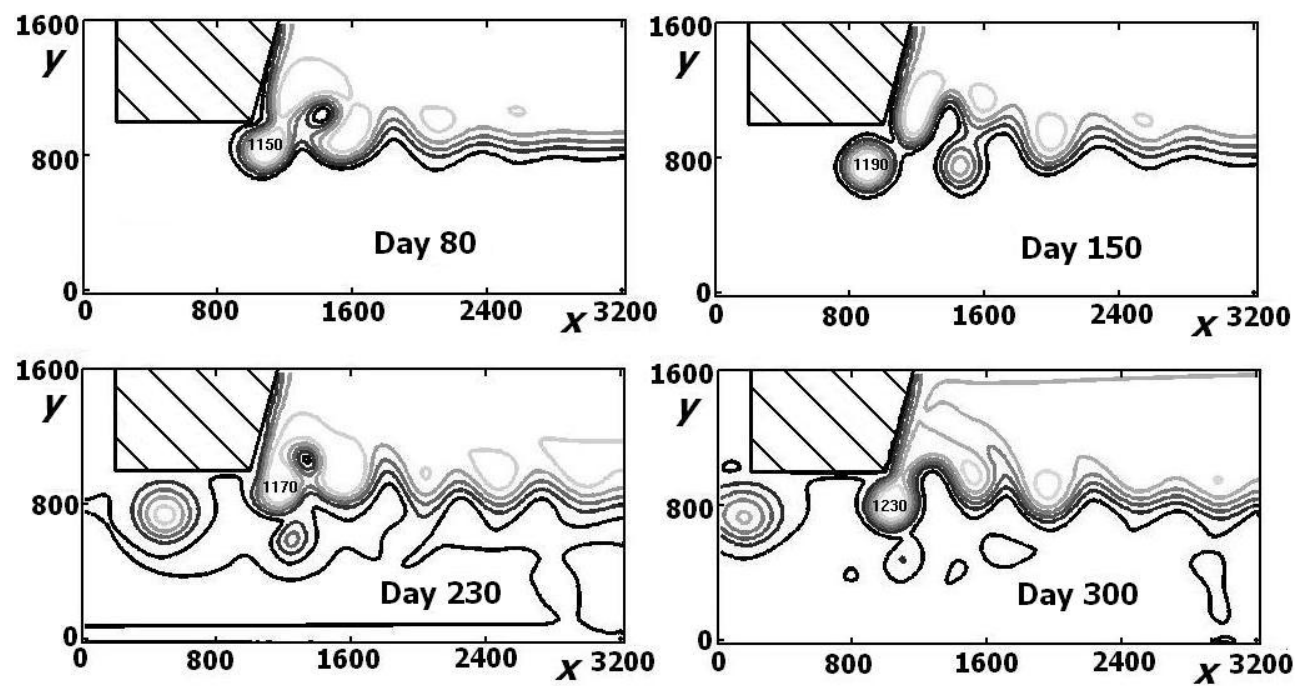

Fig. 7. Upper layer thicknesses for the case of a Concave I coastline with a sharp kink (large $\gamma)$ and a current with modest vorticity $\left(\gamma=75^{\circ}\right.$, $\alpha=0.4, h_{0}=300 \mathrm{~m}, v=700 \mathrm{~m}^{2} \mathrm{~s}^{-1}$, and $\beta=6 \times 10^{-11} \mathrm{~m}^{-1} \mathrm{~s}^{-1}$ ). Here, the eastern wall slant is too high to allow for ring production, so rings are produced just downstream of the kink, which effectively locks the position of the retroflection. Only one eddy is detached; a second one is about to be detached on day 300 .

then propagate into the retroflection area, forcing the base eddy to detach as well (not shown).

If rings shedding were completely prevented by recapturing (such as in the super-critical case of the retroflection from a straightforward no-kink slanted coast), then we would not be able to say how, and if, the retroflection paradox (Nof and Pichevin, 1996) could be circumvented. It is worth mentioning here in passing that Pichevin et al. (1999) suggest that according to their simulations, upstream rings that formed off-shore (in the northeastern part of the retroflected current) detached and ultimately reencountered the approaching current. They supposed that these events were artificial, suggesting that, in nature, such eddies are observed to be advected eastward. However, Lutjeharms (2006, p. 227) notes that at least cold cyclonic eddies (formed in the Agulhas Return Current) propagate westward 


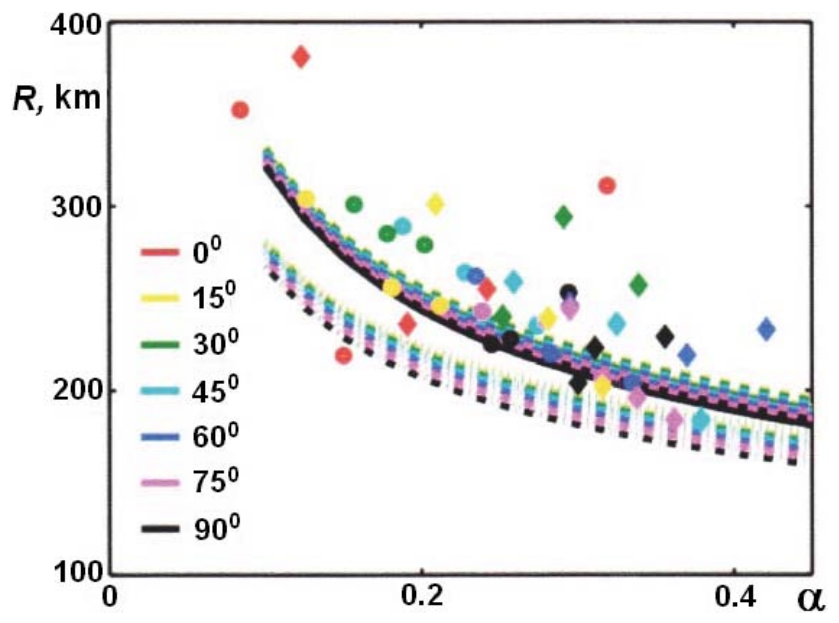

Fig. 8. Ring radii from the analytical kink model and corresponding numerical simulations for a range of eastern wall slants $(\gamma)$. The slant of the western segment is nearly zero. Modeled values of $R_{f l}$ and $R_{f u}$ are plotted against $\alpha$ for $h_{0}=0$ (solid and dashed lines, respectively) and for $h_{0}=300 \mathrm{~m}$ (dash-and-dotted and dotted lines, respectively). The numerical values of $R$ correspond to $\alpha$ being, as in $\mathrm{ZNb}$, averaged over the periods of simulations (diamonds for $h_{0}=0$ and circles for $h_{0}=300 \mathrm{~m}$ ). The numerical radii are larger than in our model because of viscosity, which spins the rings down flattening them out.

and are subsequently absorbed by the first meander encountered in their westward paths.

We also quantitatively compared analytical and numerical model results for the case of a Concave I kinked coastline. The outcomes are similar to those mentioned in $\mathrm{ZNb}$, i.e., the agreement in rings radii is good, with possible differences of about $20 \%$, on average (Fig. 8). However, propagation rates in the numerics are on average about half those in our analytical model, again because of the effect of viscosity.

\section{Agulhas rings leakage variability}

Our purpose here is not to duplicate nature point-by-point (for which a more sophisticated model subject to much longer runs is needed) but rather to point out the dynamical importance of a sudden change in the coastline slant (i.e., a kink). No-kink model simulations with a moderate coastline typical of meant SIF conditions $\left(35-40^{\circ}\right)$, lead to a sub-critical shedding regime for $\alpha>0.15$ but a critical or super-critical regime for the more realistic values of $\alpha \leq 0.15$ (Fig. 5). Therefore, the applicability of this no-kink model to real ocean conditions is poor. Moreover, the curves for $\alpha=0.1$ terminate at $\gamma=35^{\circ}$, implying that the no-kink model is invalid in such conditions because according to this model, the base eddy cannot grow in the retroflection area. Hence, we suggest that our Concave I model describes the behavior of the Agulhas retroflection better than does the no-
Table 1. Theoretically estimated (Concave I) shedding ratios as a function of the vorticity coefficient, $\alpha$.

\begin{tabular}{lllllll}
\hline$\alpha$ & 0.1 & 0.2 & 0.4 & 0.6 & 0.8 & 1.0 \\
\hline Eddyradius for SIF & 0.96 & 0.96 & 0.96 & 0.96 & 0.96 & 0.96 \\
$\begin{array}{c}\text { Eddyradius for NPR } \\
\text { Sheddingperiod for SIF }\end{array}$ & 1.04 & 1.05 & 1.06 & 1.06 & 1.06 & 1.06 \\
$\begin{array}{c}\text { Sheddingperiod for NPR } \\
\text { Eddyvelocity for SIF }\end{array}$ & 0.93 & 0.92 & 0.91 & 0.91 & 0.91 & 0.90 \\
\hline Eddyvelocity for NPR & & & & & & \\
\hline
\end{tabular}

kink model, and (Fig. 2) we take $\gamma=15^{\circ}$ as representative of NPR conditions and $\gamma=60^{\circ}$ for SIF.

Using the analytical Concave I model, we estimated SIF:NPR ratios of various shedding parameters (Table 1). All the numbers here are obtained by numerical realization of our Eqs. (2) and (3), with an error of $0.1 \%$ or less. It is seen that the intensity of ring shedding significantly decreases during SIF - i.e., eddies are produced less frequently and their velocities are lower than during NPR. Therefore, the mass transport from the Indian Ocean to the South Atlantic is weaker during SIF than during NPR (despite the non-critical regime in both cases). Note that the parameter ratios given in Table 1 are almost independent of $\alpha$.

To fit the model geometry to nature and make the horizontal scales as close as possible to their real values (Fig. 2), we adopted Concave II as representative for NPR conditions and Concave III for SIF. The SIF shedding regime near the kink (point $\mathrm{C}$ in Fig. 2) is shown in Fig. 9 for weak vorticity and shallow depth. The NPR shedding regime with the retroflection near point B is shown in Fig. 10. The retroflection latitude here is south of that for the Concave III case. Note that we moved here the strongly slanted easternmost shoreline segment out of the calculation frame. (Otherwise, the area of the numerically simulated retroflection shifts gradually to the east, as would occur during a restoration of the SIF regime.) Also, to maintain numerical stability, we had to increase the viscosity here by about $20 \%$ over that in the Concave III case. The eddy generation period for this NPR simulation is less than that for SIF (Fig. 9) because, although the first two eddies are generated almost at the same time in both cases, the third one lags noticeably in the SIF case. Also, the rings' radii are greater under NPR conditions (Fig. 10), implying that the leakage during NPR is larger than during SIF. The shed NPR eddies form a chain, mainly in the open ocean. The results are not altered appreciably for simulations with stronger vorticity and greater upper layer thickness. We note also that the Concave II and Concave III numerical simulations with closely spaced rings require higher viscosity for stability than that in Concave I simulations (Figs. 6 and 7) because of higher shear.

We calculated SIF:NPR (Concave III:Concave II) shedding-period ratios over a range of initial $\alpha$ for comparison to the theoretical Concave I results shown in Table 1. For 

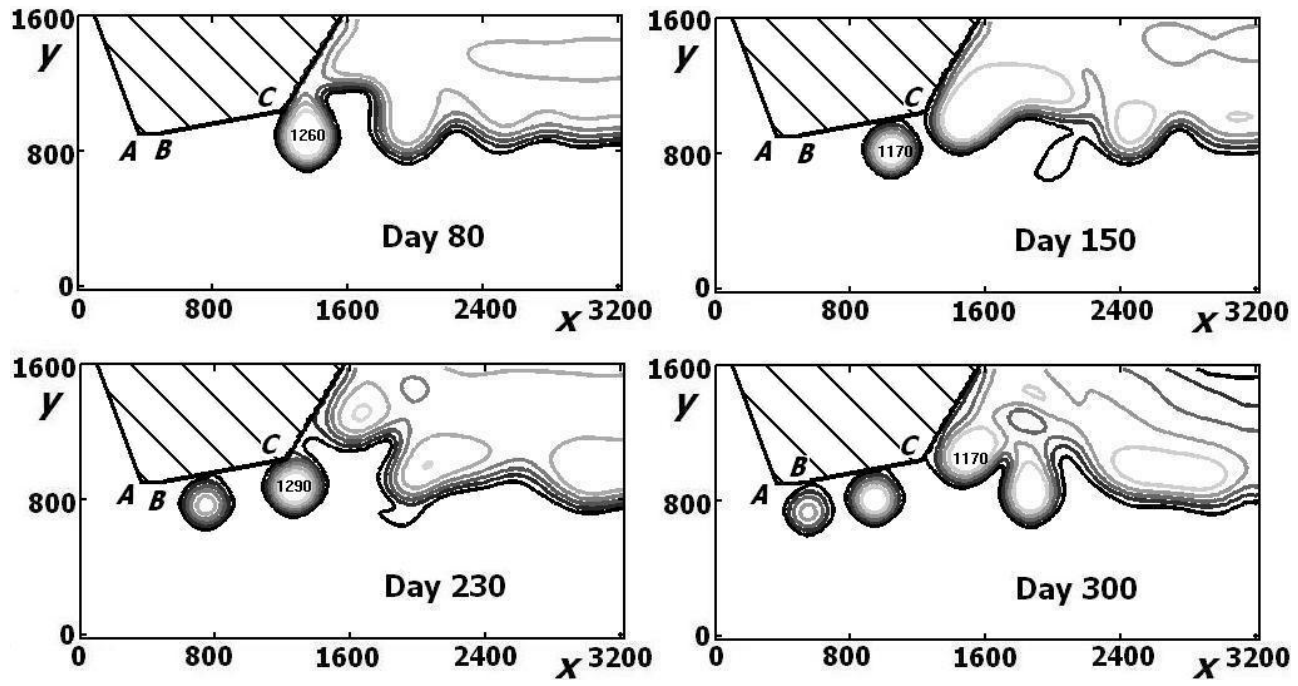

Fig. 9. Upper layer thicknesses for the case of a Concave III coastline and a modest vorticity current that retroflects near the kink $(\alpha=0.4$, $h_{0}=0, v=1000 \mathrm{~m}^{2} \mathrm{~s}^{-1}$, and $\left.\beta=6 \times 10^{-11} \mathrm{~m}^{-1} \mathrm{~s}^{-1}\right)$. This case is representative of SIF times, when the Agulhas retroflection is shifted eastward.
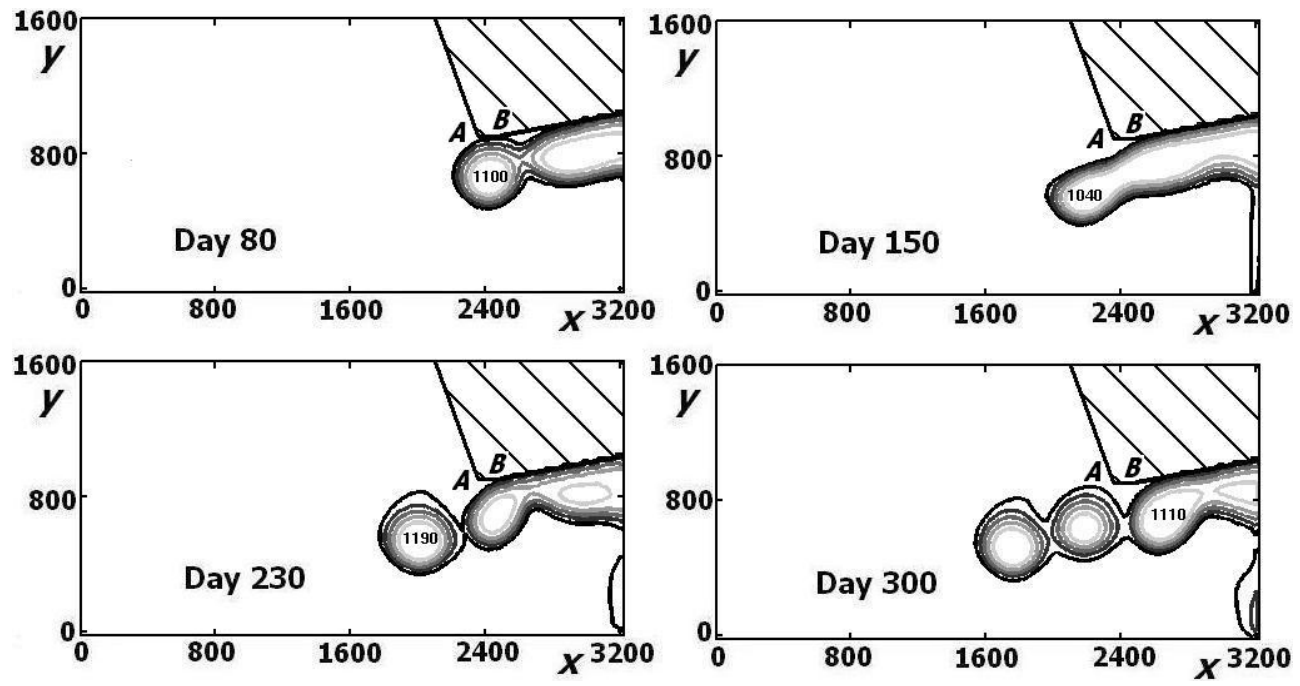

Fig. 10. Upper layer thicknesses for the case of a Concave II shoreline and a modest vorticity current that retroflects near the western termination of the slightly slanted coastline $\left(\alpha=0.4, h_{0}=0, v=1000 \mathrm{~m}^{2} \mathrm{~s}^{-1}\right.$, and $\left.\beta=6 \times 10^{-11} \mathrm{~m}^{-1} \mathrm{~s}^{-1}\right)$. This case is representative of NPR times. The strongly slanted section is moved out of the figure. Rings generation occurs more often than in Fig. 9, and the rings' radii are larger.

an initial $\alpha$ of 1.0, we obtained a mean generation period of 123 days for SIF (with a standard deviation, SD, of $40.2 \mathrm{~d}$ ) and $93 \mathrm{~d}$ for NPR (with SD of $20.5 \mathrm{~d}$ ). The SIF:NPR ratio is therefore 1.32 (SD is 0.36), which is greater than the theoretical value of 1.06 (Table 1). For $\alpha$ of 0.4 , the averaged SIF and NPR shedding periods were $118 \mathrm{~d}$ (with SD of $43.9 \mathrm{~d}$ ) and $110 \mathrm{~d}$ (with SD of $18.1 \mathrm{~d}$ ), respectively. The SIF:NPR ratio is then 1.07 ( $\mathrm{SD}$ is 0.31 ), which is very close to the theoretical value. In our simulations for $\alpha$ of 0.1 , the eddy very quickly collapsed due to the relatively greater importance of viscosity, and the estimates of average generation period have large relative errors $(60 \%)$. The obtained values were $120 \mathrm{~d}$ for SIF (with SD $71.9 \mathrm{~d}$ ) and $145 \mathrm{~d}$ for NPR (with SD $75.3 \mathrm{~d}$ ), so the ratio is 0.83 (SD is 0.47 ). It should be noted, however, that the variability in the average period was caused by viscosity rather than by the different initializations of $\alpha$. This is because during numerical runs, the eddies' PV was strongly altered by viscosity, so that the averaged values of $\alpha$ were about $0.20-0.25$ for all the simulations.

Averaged eddy radii shown were about $180 \mathrm{~km}$ for SIF and $220 \mathrm{~km}$ for NPR (Figs. 9 and 10), so SIF:NPR ratio is 0.82 , which is somewhat smaller than the theoretical value of 


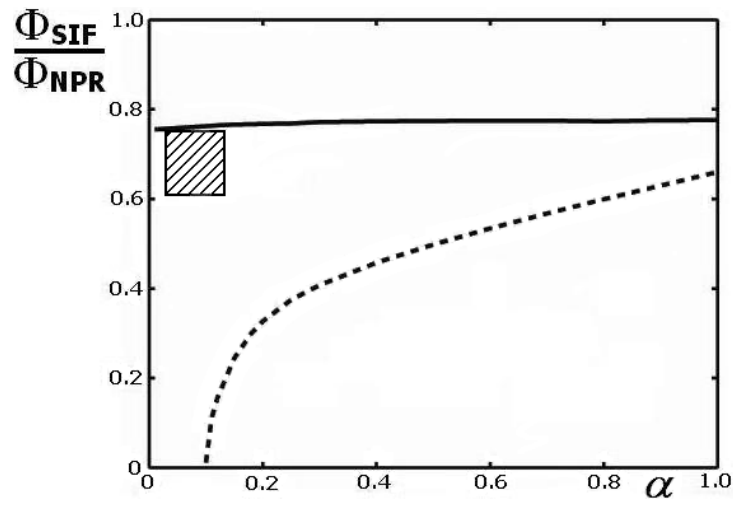

Fig. 11. Mass transports ratio $\Phi_{\mathrm{SIF}}: \Phi_{\mathrm{NPR}}$ computed analytically using the kink model (solid line) and $\mathrm{ZNb}$ no-kink model (dashed line). The no-kink coastline has a slant of $37.5^{\circ}$, the average of $60^{\circ}$ (SIF) and $15^{\circ}$ (NPR). The hatched rectangle shows the confidence area of the observational data from VSa.

0.96 (Table 1). This difference is probably again an effect of viscosity because the thickness of large NPR rings (Fig. 10) is not greater than those of the SIF rings (Fig. 9). Therefore, the ratio of the volume fluxes is expected to be comparable to our theoretical value of 0.77 (solid curve in Fig. 11). Overall, the numerical simulations confirm, at least fairly well, the results of our theoretical modeling. Also, the mean radii and shedding periods for our numerical SIF eddies are close to those in animation created by the GFDL Oceans and Climate group (see http://www.gfdl.noaa.gov/oceans-and-climate): 8 rings shed during 995 days, the averaged value of radius is about $205 \mathrm{~km}$.

We can also compare the ratio of the modeled volume fluxes $\Phi$ with observational data if we assume that the ratio of mass transport carried to the South Atlantic by rings does not differ too greatly from the ratio of the entire Agulhas leakage. According to VSa (their Fig. 1), the average ratio of Agulhas leakage to $\mathrm{AC}$ transport $\left(T_{\mathrm{AL}} / T_{\mathrm{AC}}\right)$ is $(19.2 / 60.5)=0.317$ when the retroflection is protruded westward (NPR) and $T_{\mathrm{AL}} / T_{\mathrm{AC}}=(14.2 / 67)=0.212$ when the retroflection is protruded eastward (SIF). The SIF:NPR (ratio of these ratios) is 0.67 (confidence range is approximately between 0.61 and 0.75 ), which is somewhat less than our predicted value of $\Phi_{\mathrm{SIF}}: \Phi_{\mathrm{NPR}}=0.77$ (Fig. 11). This could be due to greater dissipation occurring during the rings' longer journey from the eastern retroflection area (SIF) to the South Atlantic than from the western area (NPR). Note that the $\mathrm{ZNb}$ model with $\gamma=60^{\circ}$ for SIF (and $\gamma=15^{\circ}$ for NPR) would lead to much worse results: the considered ratio would change from about 0.4-0.6 for $\alpha=1$ to zero for $\alpha$ of less than 0.2 (which is closer to real conditions). Using the model results from Fig. 5 (bottom panels) and taking into account that rings carry usually $30-45 \%$ of the entire leakage (Doglioli et al., 2006; Van Sebille et al., 2010), we conclude that for the observations of VSa, $\alpha$ was between 0.03 and 0.13. Even for an average value of the coastal slant (say, $\gamma=37.5^{\circ}$ ), the agreement of no-kink model results with observational data for natural values of $\alpha$ is poor (Fig. 11). In this figure, we plotted the $\Phi_{\mathrm{SIF}}: \Phi_{\mathrm{NPR}}$ versus $\alpha$ for the kink and no-kink (ZNb) models, as well as the confidence region for the data from VSa. It is seen that the curve for the kink model almost touches the confidence area, whereas the no-kink curve goes to zero. (The range of $\alpha$ where the $\Phi_{\mathrm{SIF}}: \Phi_{\mathrm{NPR}}$ is zero corresponds to the super-critical case where the leakage is shut down).

Finally, using a $\Phi_{\mathrm{SIF}}: \Phi_{\mathrm{NPR}}$ of 0.77 (Fig. 11) and keeping in mind that the ratio of incoming fluxes for SIF and NPR is $1.10-1.15$ (VSa), we conclude that the ratio of outflows is about $0.85-0.90$, implying that the kinked coastline plays a defining role in the anti-correlation between the incoming Agulhas flux and the outgoing leakage to the South Atlantic.

\section{Summary and conclusions}

Using both analytical and numerical models, we showed that the South African coastline geometry exerts a fundamental control on the production of Agulhas eddies and, therefore, the leakage into the South Atlantic. Namely, the coastal kink acts like a valve for the leak. In contrast to what our intuition suggests - that strong flows will be associated with strong leaks - the analytical model with kink implies that smaller leaks occur during times of strong incoming flux (SIF).

We also showed that, for the SIF periods, the kink model gives significantly better results than the straight-coast model in the sense that the difference between the predicted eddy mass flux and the observations is 3-4 times smaller. For NPR, the difference between the concave model and the straight coastline model is insignificant because the angle between the two coastal segments in this case is very close to $180^{\circ}$. The main aspect of the kink model is that east of the kink the coastline slant is too high to allow for production of rings whereas the slant on the west allows rings production. As a result, the production of rings is allowed in a manner that is quite different from that implied by the mean slant. More importantly, the kink locks the position of the retroflection to just downstream of the kink.

To begin with, we considered a (Concave I) coastline consisting of two straight sections: a south-facing zonal segment and an eastern slanted segment (Figs. 2 and 3). We developed a non-linear analytical model with which we examined the dependency of ring formation, radii, and detachment period, on the coastline slant angle, PV of the formed eddies, and the thickness of the undisturbed upper layer. In contrast to the no-kink conclusion of $\mathrm{ZNb}$, there are no critical slant angles in the Concave I case (Figs. 4 and 5). Rather, when the slant of the non-zonal coastal section is close to $90^{\circ}$, the shedding regime is almost critical, i.e., the shedding is weak but it is not arrested. To access this finding, we carried out numerical simulations the results of which are in fair agreement with the predictions of our analytical model (Figs. 6 and 7). 
To bring our calculations still closer to reality, we also conducted numerical simulations of Concave II and Concave III cases, where the coastline geometry more satisfactorily fits the actual geography near the NPR and SIF positions of the retroflected current (Fig. 2). The Concave II case is taken to be representative of NPR times, and the Concave III case is taken to be representative of SIF. We see (Figs. 9 and 10) that the intensity of eddy shedding decreases during SIF relative to NPR. Therefore, the mass flux going into rings noticeably weakens during SIF, which is in qualitative agreement with our theoretical results (Fig. 11). Both the theoretical and numerical results indicate that when the Agulhas retroflection protrudes eastward, the ratio $\Phi_{\mathrm{SIF}}$ decreases sufficiently strongly (to about $0.77 \Phi_{\mathrm{NPR}}$ ) to explain the observed anticorrelation between the incoming flux and the outgoing leakage to the South Atlantic. Indeed, the observed ratio of incoming fluxes for SIF and NPR is 1.10-1.15; therefore, the ratio of outflows is about $0.85-0.90$. On the whole, a comparison of our results with VSa (Fig. 11) suggests that our model is consistent with the observed anti-correlation between the $\mathrm{AC}$ transport and the Agulhas leakage. Using the earlier $\mathrm{ZNb}$ model instead of the new kink model presented here would lead to significantly worse results for leakage via eddies because even the averaged value of the slant near the point of retroflection becomes super-critical (Fig. 11).

The analytical kink model is successfully applied to the case of a weak La-Niña (1986-1987): the error in fitting the observations of mass flux going into eddies is on average 3-4 times less than in the no-kink model simulations. However, it is possible that, as noted by Van Sebille (2009), the no-kink model could be better applied to the strong La-Niña events like the early Agulhas retroflection observed in 2000-2001 (see also, De Ruijter et al., 2004) when eddies shedding was nearly shut down during this period. One possible explanation for better applicability of the no-kink model is that during this early retroflection event, the AC was strongly interacting with dipoles in the Mozambique Basin. This could result in an $\mathrm{AC}$ detachment in the area where the coastline slant does not (yet) change significantly. In view of Pichevin et al. (2009), we expect the no-kink model to be preferable when the $\mathrm{AC}$ detaches from the coast somewhere in between East London and Durban, where the coastline is relatively straight. We leave these questions, however, for future investigations.

Acknowledgements. The study was supported by NASA Doctoral Fellowship Grant NNG05GP65H; LANL/IGPP Grant (1815); NSF (OCE-0752225, OCE-9911342, OCE-0545204, OCE-0241036), BSF (2006296), and NASA (NNX07AL97G). V. Zharkov was also funded by the Jim and Shelia O'Brien Graduate Fellowship. We are grateful to Steve Van Gorder for helping in the numerical simulations. We also thank Donna Samaan for helping in preparation of the manuscript and Tonya Clayton for assistance in improving the style.

Edited by: E. J. M. Delhez
Table A1. List of symbols.

\begin{tabular}{|c|c|}
\hline $\mathrm{AC}$ & Agulhas Current \\
\hline$C_{x}$ & eddy migration rate in the zonal direction \\
\hline$C_{y}$ & eddy migration rate in the meridional direction \\
\hline$C_{x f}$ & zonal eddy migration rate after detachment \\
\hline$C_{x l}, C_{x u}$ & $\begin{array}{l}\text { values of } C_{x f} \text { for eddies with radii } R_{f l}, R_{f u} \text {, } \\
\text { respectively }\end{array}$ \\
\hline$d$ & distance between consecutive eddies \\
\hline$d_{1}$ & width of incoming current \\
\hline$d_{2}$ & width of retroflected current \\
\hline$f$ & Coriolis parameter \\
\hline$f_{0}$ & approximate absolute value of $f$ at the eddy center \\
\hline$g^{\prime}$ & reduced gravity \\
\hline$H$ & upper layer thickness outside the retroflection area \\
\hline$h$ & upper layer thickness \\
\hline$h_{0}$ & upper layer thickness at the wall \\
\hline$\tilde{\mathrm{h}}$ & $\begin{array}{l}\text { upper layer thickness in the stagnant wedge } \\
\text { between the incoming and retroflected currents }\end{array}$ \\
\hline NPR & normal position of retroflection \\
\hline PV & potential vorticity \\
\hline$Q$ & mass flux of the incoming current \\
\hline$q$ & mass flux of the retroflected current \\
\hline$R$ & radius of the eddy (a function of time) \\
\hline$R_{f}$ & radius of the eddy at the moment of detachment \\
\hline$R_{f l}, R_{f u}$ & lower and upper boundaries of $R_{f}$ \\
\hline SIF & strong incoming flux \\
\hline $\mathrm{Sv}$ & Sverdrup $\left(10^{6} \mathrm{~m}^{3} \mathrm{~s}^{-1}\right)$ \\
\hline$t$ & time \\
\hline$t_{f}$ & period of eddy generation \\
\hline$t_{f l}, t_{f u}$ & lower and upper boundaries of $t_{f}$ \\
\hline VSa & Van Sebille et al. (2009b) \\
\hline$x, y$ & $\begin{array}{l}\text { zonal and meridional coordinate axes in the } \\
\text { moving system }\end{array}$ \\
\hline $\mathrm{ZNa}$ & Zharkov and Nof (2008a) \\
\hline $\mathrm{ZNb}$ & Zharkov and Nof (2008b) \\
\hline$\alpha$ & vorticity coefficient (twice the Rossby number) \\
\hline$\beta$ & meridional gradient of the Coriolis parameter \\
\hline$\gamma$ & $\begin{array}{l}\text { slant of coastline (i.e., angle of derivation from } \\
\text { zonal) for the no-kink model and slant of the } \\
\text { eastern section of coastline for the kink model }\end{array}$ \\
\hline$\delta_{1}, \delta_{2}$ & $\begin{array}{l}\text { differences between the eddy radius and current } \\
\text { widths } d_{1}, d_{2} \text {, respectively }\end{array}$ \\
\hline$\Delta \rho$ & $\begin{array}{l}\text { difference between densities of lower } \\
\text { and upper layer }\end{array}$ \\
\hline$v$ & viscosity (in numerics) \\
\hline$\rho$ & upper layer density \\
\hline$\Phi$ & $\begin{array}{l}\text { ratio of mass flux going into eddies and incoming } \\
\text { mass flux }\end{array}$ \\
\hline$\Phi_{1}, \Phi_{u}$ & $\begin{array}{l}\text { values of } \Phi \text { for eddies with radii } R_{f l}, R_{f u} \text {, } \\
\text { respectively }\end{array}$ \\
\hline
\end{tabular}




\section{References}

Arruda, W. Z., Nof, D., and O'Brien, J. J.: Does the Ulleung eddy owe its existence to $\beta$ and nonlinearities?, Deep-Sea Res., 51, 2073-2090, 2004.

Biastoch, A., Böning, C. W., and Lutjeharms, J. R. E.: Agulhas leakage dynamics affects decadal variability in Atlantic overturning circulation, Nature, 456, 489-492, 2008.

Bleck, R. and Boudra, D.: Wind-driven spin-up in eddy-resolving ocean models formulated in isopycnic and isobaric coordinates, J. Geophys. Res., 91, 7611-7621, 1986.

Boudra, D. B. and Chassignet, E. P.: Dynamics of the Agulhas retroflection and ring formation in a numerical model, I. The vorticity balance, J. Phys. Oceanogr., 18, 280-303, 1988.

Byrne, A. D., Gordon, A. L., and Haxby, W. F.: Agulhas eddies: A synoptic view using Geosat ERM data, J. Phys. Oceanogr., 25, 902-917, 1995.

Chassignet, E. P. and Boudra, D. B.: Dynamics of the Agulhas retroflection and ring formation in a numerical model, II. Energetics and ring formation, J. Phys. Oceanogr., 18, 304-319, 1988.

De Ruijter, W. P. M.: Asymptotic analysis of the Agulhas and Brazil Current systems, J. Phys. Oceanogr., 12, 361-373, 1982.

De Ruijter, W. P. M. and Boudra, D. B.: The wind-driven circulation in the South Atlantic - Indian Ocean, I. Numerical experiments in a one-layer model, Deep-Sea Res., 32, 557-574, 1985.

De Ruijter, W. P. M., Biastoch, A., Drijfhout, S. S., Lutjeharms, J. R. E., Matano, R. P., Pichevin, T., Van Leeuwen, P. J., and Weijer, W.: Indian Atlantic interocean exchange: Dynamics, estimation and impact, J. Geophys. Res., 104, 20885-20910, 1999.

De Ruijter, W. P. M., Van Aken, H. M., Beier, E. J., Lutjeharms, J. R. E., Matano, R. P., and Schouten, M. W.: Eddies and dipoles around South Madagascar: formation, pathways and large-scale impact, Deep-Sea Res., 51, 383-400, 2004.

Doglioli, A. M., Veneziani, M., Blanke, B., Speich, S., and Grifta, A.: A Lagrangian analysis of the Indian Atlantic interocean exchange in a regional model, Geophys. Res. Lett., 33, L14611, doi:10.1029/2006GL026498, 2006.

Esper, O., Versteegh, G. J. M., Zonneveld, K. A. F., and Willems, H.: A palynological reconstruction of the Agulhas Retroflection (South Atlantic Ocean) during the Late Quaternary, Global Planet. Change, 41, 31-62, 2004.

Ffield, A., Toole, J., and Wilson, D.: Seasonal circulation in the South Indian Ocean, Geophys. Res. Lett., 24, 2773-2776, 1997.

Goni, G. J., Garzoli, S. L. Roubicek, A. J., Olson, D. B., and Brown, O. B.: Agulhas ring dynamics from TOPEX/POSEIDON satellite altimeter data, J. Mar. Res., 55, 861-883, 1997.

Gordon, A. L., Lutjeharms, J. R. E., and Gründlingh, M. L.: Stratification and circulation at the Agulhas Retroflection, Deep-Sea Res., 34, 565-599, 1987.

Lutjeharms, J. R. E.: The Agulhas Current, Springer-Verlag, BerlinHeidelberg-New York, XIV, 330 pp., 2006.

Lutjeharms, J. R. E. and Van Ballegooyen, R. C.: Topographic control in the Agulhas Current system, Deep-Sea Res., 31, 13211337, 1984.

Lutjeharms, J. R. E. and Van Ballegooyen, R. C.: The retroflection of the Agulhas Current, J. Phys. Oceanogr., 18, 1570-1583, 1988a.

Lutjeharms, J. R. E. and Van Ballegooyen, R. C.: Anomalous upstream retroflection in the Agulhas current, Science, 240, 1770-
1772, 1988b.

Matano, R. P., Simionato, C. G., De Ruijter, W. P. M., Van Leeuwen, P. J., Strub, P. T., Chelton, D. B., and Schlax, M. G.: Seasonal variability in the Agulhas Retroflection region, Geophys. Res. Lett., 25, 4361-4364, 1998.

Nof, D.: On the $\beta$-induced movement of isolated baroclinic eddies, J. Phys. Oceanogr., 11, 1662-1672, 1981.

Nof, D.: On the migration of isolated eddies with application to Gulf stream rings, J. Mar. Res., 31, 399-425, 1983.

Nof, D.: The momentum imbalance paradox revisited, J. Phys. Oceanogr., 35, 1928-1939, 2005.

Nof, D. and Pichevin, T.: The retroflection paradox, J. Phys. Oceanogr., 26, 2344-2358, 1996.

Nof, D. and Pichevin, T.: The ballooning of outflows, J. Phys. Oceanogr., 31, 3045-3058, 2001.

Orlanski, I.: A simple boundary condition for unbounded hyperbolic flows, J. Comput. Phys., 21, 251-269, 1976.

Ou, H. W. and De Ruijter, W. P. M.: Separation of an internal boundary current from a curved coast line, J. Phys. Oceanogr., 16, 280-289, 1986.

Pichevin, T., Nof, D., and Lutjeharms, J. R. E.: Why are there Agulhas Rings? J. Phys. Oceanogr., 29, 693-707, 1999.

Pichevin, T., Herbette, S., and Floc'h, F.: Eddy formation and shedding in a separating boundary current, J. Phys. Oceanogr., 39, 1921-1934, 2009.

Quartly, G. D. and Srokosz, M. A.: SST Observations of the Agulhas and East Madagascar Retroflections by the TRMM Microwave Imager, J. Phys. Oceanogr., 32, 1585-1592, 2002.

Reason, C. J. C., Lutjeharms, J. R. E., Hermes, J., Biastoch, A., and Roman, R. E.: Inter-ocean fluxes south of Africa in an eddypermitting model, Deep-Sea Res. Pt. II, 50, 281-298, 2003.

Schouten, M. W., De Ruijter, W. P. M., Van Leeuwen, P. J., and Lutjeharms, J. R. E.: Translation, decay and splitting of Agulhas rings in the south-eastern Atlantic ocean, J. Geophys. Res., 105, 21913-21925, 2000.

Shannon, L. V.: The Benguela ecosystem: Part I. Evolution of the Benguela, physical features and processes, Oceanogr. Mar. Biol., 23, 105-182, 1985.

Shannon, L. V., Agenbag, J. J., Walker, N. D., and Lutjeharms, J. R. E.: A major perturbation in the Agulhas retroflection area in 1986, Deep-Sea Res., 37, 493-512, 1990.

Van Aken, H. M., Van Veldhoven, A. K., Veth, C., De Ruijter, W. P. M., Van Leeuwen, P. J., Drijfhout, S. S., Whittle, C. P., and Rouault, M.: Observations of a young Agulhas ring, Astrid, during MARE in March 2000, Deep-Sea Res., 50, 167-195, 2003.

Van Sebille, E.: Assessing Agulhas leakage, Proefschrift ter verkrijging van de graad van doctor aan de Universiteit Utrecht, 165 pp., 2009.

Van Sebille, E., Biastoch, A., Van Leeuwen, P. J., and De Ruijter, W. P. M.: A weaker Agulhas current leads to more Agulhas leakage, Geophys. Res. Lett., 36, L03601, doi:10.1029/2008GL036614, 2009a.

van Sebille, E., Barron, C. N., Biastoch, A., van Leeuwen, P. J., Vossepoel, F. C., and de Ruijter, W. P. M.: Relating Agulhas leakage to the Agulhas Current retroflection location, Ocean Sci., 5, 511-521, doi:10.5194/os-5-511-2009, 2009b.

Van Sebille, E., Van Leeuwen, P. J., Biastoch, A., and De Ruijter, W. P. M.: On the fast decay of Agulhas rings, J. Geophys. Res., 115, C0310, doi:10.1029/2009JC005585, 2010. 
Weijer, W., De Ruijter, W. P. M., Dijkstra, H. A., and Van Leeuwen, P. J.: Impact of interbasin exchange on the Atlantic Overturning Circulation, J. Phys. Oceanogr., 29, 2266-2284, 1999.

Weijer, W., De Ruijter, W. P. M., Sterl, A., and Drijfhout, S. S.: Response of the Atlantic overturning circulation to South Atlantic sources of buoyancy, Global Planet. Change, 34, 293-311, 2002.
Zharkov, V. and Nof, D.: Retroflection from slanted coastlinescircumventing the "vorticity paradox", Ocean Sci., 4, 293-306, doi:10.5194/os-4-293-2008, 2008a.

Zharkov, V. and Nof, D.: Agulhas ring injection into the South Atlantic during glacials and interglacials, Ocean Sci., 4, 223-237, doi:10.5194/os-4-223-2008, 2008 b. 